\title{
Functional Regeneration in a Rat Parkinson's Model after Intrastriatal Grafts of Glial Cell Line-Derived Neurotrophic Factor and Transforming Growth Factor $\beta_{1}$-Expressing Extra-Adrenal Chromaffin Cells of the Zuckerkandl's Organ
}

\author{
Emilio Fernandez Espejo, ${ }^{1}$ M. Carmen Gonzalez-Albo, ${ }^{2}$ Joao-Paulo Moraes, ${ }^{1}$ Fadwa El Banoua, ${ }^{1}$ \\ Juan A. Flores, ${ }^{1}$ and Isabel Caraballo ${ }^{1}$ \\ 1Departamento de Fisiologia Medica y Biofisica, Universidad de Sevilla, E-41009 Sevilla, Spain, and 2/nstituto Cajal, \\ Consejo Superior de Investigaciones Cientificas, E-28002 Madrid, Spain
}

Intrabrain transplantation of chromaffin cell aggregates of the Zuckerkandl's organ, an extra-adrenal paraganglion that has never been tested for antiparkinsonian treatment, induced gradual improvement of functional deficits in parkinsonian rats. These beneficial effects were related to long survival of grafted cells, striatal reinnervation, and enhancement of dopamine levels in grafted striatum. Grafted cells were not dopaminergics, but they expressed glial cell line-derived neurotrophic factor (GDNF) and transforming growth factor- $\beta_{1}$. These factors were detected in the host striatal tissue, indicating that chromaffin cells secreted them after grafting. Because glial cell linederived neurotrophic factor possesses neurorestorative prop- erties over dopaminergic neurons, and transforming growth factor- $\beta_{1}$ is a cofactor that potentiates the neurotrophic actions of GDNF, functional regeneration was likely caused by the chronic trophic action of neurotrophic factors delivered by longsurviving grafted cells. This work should stimulate research on the clinical applicability of transplants of the Zuckerkandl's organ in Parkinson's disease.

Key words: Parkinson's disease; graft; Zuckerkandl's organ; extra-adrenal cell; adrenal cell; glial cell line-derived neurotrophic factor; transforming growth factor- $\beta_{1}$; stereology; 6-hydroxydopamine
Parkinson's disease is caused by the loss of dopaminergic neurons of substantia nigra projecting to striatum. The most prevalent therapy is levodopa administration, but it is not efficacious after several years of treatment. In search of an alternative therapy, intrastriatal grafts of dopamine-secreting cells from neural or chromaffin tissues, such as fetal mesencephalon, adrenal medulla, and carotid body, has been reported to ameliorate functional deficits in animal models of Parkinson's disease (Bolam et al., 1987; Bohn et al., 1987; Goetz et al., 1991; Espejo et al., 1998; Luquin et al., 1999). Transplantation is considered a promising treatment for human Parkinson's disease, but its clinical use is still restricted to few cases. The major limiting factors regarding fetal mesencephalic cells are the ethical, practical, and safety issues associated with tissue derived from aborted human fetuses and the difficulty in obtaining sufficient viable embryonic mesencephalic tissue (Dunnett and Björklund, 1999). Adrenal cells are no longer used because their long-term survival is very poor in the brain, and beneficial effects are transient either in Parkinson's

\footnotetext{
Received Feb. 12, 2001; revised Sept. 27, 2001; accepted Oct. 1, 2001.

This work was supported by grants to E.F.E. from Spanish Ministerio de Educacion y Cultura (PM98-015) and Plan Andaluz de Investigacion (CVI-127) and to M.C.G.-A. from Spanish Ministerio de Ciencia y Tecnologia (PM99-0105). We thank Drs. Javier DeFelipe, Jon Arellano (Madrid, Spain), and Ana Fernandez Rodriguez (Sevilla, Spain) for morphological help, Drs. Julia Garcia-Hirschfield (Valencia, Spain) and Juan J. Toledo-Aral (Sevilla, Spain) for the generous gift of lab material, Dr. Javier Miñano (Sevilla, Spain) for HPLC measurements, Dr. L. Stinus (France) for helpful assistance, and Antonio León (Sevilla, Spain) for animal care.

Correspondence should be addressed to E. F. Espejo, Departamento de Fisiologia Medica y Biofisica, Universidad de Sevilla, Avenida Sanchez Pizjuan 4, E-41009 Sevilla, Spain. E-mail: efespejo@us.es.

Copyright (ㄷ) 2001 Society for Neuroscience $\quad 0270-6474 / 01 / 219888-08 \$ 15.00 / 0$
}

patients or in animals (Yurek and Sladek, 1990). The clinical effects of glomus cell transplants still have to be investigated.

Another grafting strategy is to introduce potentially neuroprotective molecules that stimulate regeneration in the damaged nigrostriatal system. Among these molecules, glial cell linederived neurotrophic factor (GDNF) has potent in vivo effects (Lin et al., 1993; Tomac et al., 1995; Beck et al., 1995; Gash et al., 1998), and promising results have been obtained with fibroblasts engineered to secrete GDNF (Tseng et al., 1997) or viral vectors expressing GDNF (Mandel et al., 1997; Kirik et al., 2000). In this context, the antiparkinsonian effects of cell grafts of the chromaffin lineage are attributed not only to dopamine release from grafted cells but also to dopaminergic reinnervation of the denervated striatum (Freed et al., 1981; Bohn et al., 1987; Espejo et al., 1998; Dunnett and Björklund, 1999; Luquin et al., 1999), and chromaffin cells are known to express and release GDNF (Unsicker and Krieglstein, 1996; O'Connor, 1999). However, as explained, adrenal chromaffin cells induce a transient amelioration, a fact that perhaps has precluded the use of extra-adrenal cells, of similar embryological origin.

Nevertheless, the extra-adrenal tissue is not homogeneous, and different extra-adrenal paraganglia can be found. Among them, the Zuckerkandl's organ is the biggest extra-adrenal paraganglion (although its size is reduced over life), representing an important source of circulant catecholamines (Ahonen et al., 1987). It is located adjacent to the lower abdominal aorta and can be easily removed (Testut and Latarjet, 1978; Bohn et al., 1982). In the present study, the antiparkinsonian efficacy of the Zuckerkandl's organ grafts was tested in rats in search for an alternative source of cells for cell replacement in Parkinson's disease. Here we show 
that intrastriatal transplantation of extra-adrenal chromaffin cells of the Zuckerkandl's organ induce progressive improvement of functional deficits in parkinsonian rats and that these chromaffin cells present a long survival after grafting, unlike adrenal chromaffin cells that only induce a transiently beneficial effect.

\section{MATERIALS AND METHODS}

Unilateral 6-hydroxydopamine-induced nigra lesion. Wistar rats were housed at a regulated temperature $\left(22 \pm 1^{\circ} \mathrm{C}\right)$ in a $12 \mathrm{hr}$ light/dark cycle (lights on at 8:00 A.M.). Food and water were available ad libitum. Thirty minutes before 6-hydroxydopamine (6-OHDA; Research Biochemicals, Natick, MA) lesion, rats were injected with the antibiotic ceftriazone (10 $\mathrm{mg} / 0.3 \mathrm{ml}$, i.m. $)$, and desipramine $(15 \mathrm{mg} / \mathrm{kg}$, i.p.) to protect noradrenergic terminals from 6-OHDA toxicity. Rats were anesthetized with chloral hydrate $(425 \mathrm{mg} / \mathrm{kg}$, i.p.) and placed in a Kopf stereotaxic apparatus with the incisor bar set $3.3 \mathrm{~mm}$ below the interaural line. Saline solution $(1.2 \mu \mathrm{l} / \mathrm{site})$ containing 6-OHDA $(5 \mu \mathrm{g} / \mu \mathrm{l})$ and $0.2 \%$ ascorbic acid was injected over 5 min with a blunted 30 gauge cannula at the following coordinates with respect to bregma: anteroposterior (AP) $-5.2,-5.4$, lateral $(\mathrm{L})-2.2$, and ventral $(\mathrm{V})-8.2$ (Paxinos and Watson, 1997). The cannula was left in place for 1 min after injection. Control rats followed the same protocol except that a 6-OHDA-free solution $(0.9 \%$ $\mathrm{NaCl}$ and $0.2 \%$ ascorbic acid) was injected.

Grafting procedure. Extra-adrenal paraganglia and adrenal glands were obtained from young rats (200-250 gm) under anesthesia (chloral hydrate, $425 \mathrm{mg} / \mathrm{kg}$, i.p.). Abdominal skin and muscles were incised, and intestinal asae were displaced to expose the abdominal aorta. After carefully dissecting retroperitoneum, the Zuckerkandl's organ was located lying on the abdominal aorta between the emergence of inferior mesenteric and iliac arteries, and the adrenal gland was located on the superior pole of the left kidney. Then, the paraganglion and the adrenal gland were gently removed and cleaned of surrounding adipose tissue, and the adrenal medulla was isolated from the surrounding cortical tissue. They were then coronally sectioned, and each section was trimmed into pieces of $\sim 0.75 \mathrm{~mm}^{3}$ in volume. The tissue for grafting was incubated for $20 \mathrm{~min}$ in a $\mathrm{Ca}^{2+}$ - and $\mathrm{Mg}^{2+}$-free Tyrode's solution with collagenase $(1 \mathrm{mg} / \mathrm{ml})$, trypsin $(1 \mathrm{mg} / \mathrm{ml})$, and DNase $(0.5 \mathrm{mg} / \mathrm{ml})($ Espejo et al., 1998). After enzymatic treatment, cell aggregates were resuspended in $5 \mathrm{ml}$ of normal Tyrode's solution to remove the enzymes. Afterward, an anesthetized parkinsonian or control animal was placed into a Kopf stereotaxic apparatus. A burr hole was drilled over the denervated striatum, and a blunted 23 gauge cannula, connected to a $2 \mu 1$ Hamilton syringe, was lowered to the injection site (coordinates: AP $+1.5, \mathrm{~L}-3$, and $\mathrm{V}-5.5$ ) (Paxinos and Watson, 1997). Tyrode's solution $(2 \mu \mathrm{l})$ containing a cell aggregate of extra-adrenal paraganglia, adrenal medulla or without it (control and sham-grafted rats) was injected. Pieces used for transplantation were randomly chosen. All the experiments were performed in accordance with the European Communities Council Directive for the employment of laboratory animals (86/609/EEC).

Behavioral study. Rats were randomly assigned to four groups: 6-OHDA-lesioned with organ of Zuckerkandl's graft (referred to as "Zuckerkandl group"; $n=12$ ), 6-OHDA-lesioned with adrenal graft (referred to as "adrenal group"; $n=10$ ), 6-OHDA-lesioned with sham graft (referred to as "sham-grafted group"; $n=10$ ), and sham nigra lesion with sham graft (referred to as "control group"; $n=10$ ). Motor and sensorimotor deficits were evaluated $15 \mathrm{~d}$ before and after unilateral nigra lesion or sham operation, and at 1,2,3, and 5 months after grafting. For behavioral study, we followed a methodology previously described (Ungerstedt and Arbuthnott, 1970; Marshall, 1979; Schwarting and Huston, 1996; Espejo et al., 1998). In summary, locomotor directional bias was evaluated by quantifying ipsilateral rotations induced by amphetamine $(5 \mathrm{mg} / \mathrm{kg}$, i.p.). The number of ipsiversive rotations were quantified from 30-90 min after injection, and only those animals observed to make $>420$ turns per hour were used for grafting. Forelimb asymmetry was evaluated by the cylinder test (Kirik et al., 2000), in which the animal is allowed to move freely in a transparent cylinder $(50 \times 30 \mathrm{~cm})$ until it has displayed 20 rearing postures, during which it leans at least one paw against the cylinder wall. The number of left and right forepaw contacts are counted, and the data are presented as percentage of right forepaw contacts (right paw use ratio). Hemiparkinsonian rats with lesion in the left substantia nigra present a significant impairment in the contralateral (right) paw use. Sensorimotor orientation was evaluated through the whisker-touch and odor tests. These tests are based on the impaired orientation of hemiparkinsonian rats to stimuli presented contralaterally
(Stricker and Zigmond, 1986). In the whisker touch test, the orientation latency toward a tactile stimulus is measured. Thus, a thin probe is approached from the right side, and after gently touching the vibrissae, the latency for moving the head toward the probe is quantified (whiskertouch). In the odor test, head orientation latency trying to avoid an aversive stimulus is measured. Thus, a probe with the tip impregnated in ammonia is approached from the right side near the nose, and the latency for shaking the head off the probe is quantified. Behavioral data in the cylinder test was analyzed by using Student's $t$ test (independent groups) at 1 and 5 months after grafting. Two-way ANOVA was used for analyzing the other tests (group, between variable; time point, within variable) followed by one-way ANOVA and Newman-Keuls test for comparisons among groups at the same time point. If distribution was found not to be normal and variance was not homogeneous, as revealed by the $F$ test, the data were logarithmically $(\log [\mathrm{x}])$ transformed before ANOVA analysis. Sphericity of repeated measures was always assessed before ANOVA treatment by using the Mauchly's W test, to reveal that sphericity was not violated.

Immunohistochemistry and immunofluorescence. Rats were transcardially perfused with $150 \mathrm{ml}$ of PBS followed by $500 \mathrm{ml}$ ice-cold $4 \%$ paraformaldehyde in $0.1 \mathrm{M}$ phosphate buffer (PB), $\mathrm{pH}$ 7.2-7.4. After dissection the brains were post-fixed overnight in the same fixative at $4{ }^{\circ} \mathrm{C}$ and immersed in $25 \%$ sucrose in PBS for cryoprotection before being stored. Pieces of the Zuckerkandl's organ or the adrenal medulla not used for transplantation were immersed in $4 \%$ paraformaldehyde in 0.1 M PB overnight. Coronal sections of brains, paraganglia, or adrenal medulla (50- $\mu \mathrm{m}$-thick) were cut on a vibratome and collected in PBS. The sections taken from the pieces of paraganglia and adrenal medulla were used for tyrosine hydroxylase (TH) and dopamine- $\beta$-hydroxylase (DBH) immunofluorescence. The sections taken from five grafted brains with Zuckerkandl's organ were mounted onto glass slides in sequence and subsequently used for thionin staining (Nissl method), TH and DBH immunohistochemistry, and TH-DBH immunofluorescence. Regarding the remainder grafted brains with extra-adrenal cells $(n=7)$, four brains were used for HPLC and ELISA analyses (see corresponding section), and sections taken from three brains were subsequently stained with GDNF, transforming growth factor (TGF)- $\beta_{1}$, and acid fibroblast growing factor (aFGF) antisera. Finally, 15 brains of controls $(n=5)$, sham-grafted rats $(n=5)$, and rats with adrenal transplants $(n=5)$ were also sectioned and used for TH immunohistochemistry, and 12 brains from controls $(n=4)$, sham-grafted rats $(n=4)$, and rats with adrenal transplants $(n=4)$ were used for HPLC and ELISA analyses.

For immunohistochemistry, endogenous peroxidase activity was quenched by placing sections into $3 \% \mathrm{H}_{2} \mathrm{O}_{2}$ in 0.05 Tris buffer, $\mathrm{pH} 7.6$, for $10 \mathrm{~min}$. Then sections were incubated in PBS and $0.25 \%$ Triton X-100 (PBS-T) with 3\% normal goat serum (Vector Laboratories, Burlingame, CA) for $1 \mathrm{hr}$ to block nonspecific sites. Sections were incubated overnight with monoclonal mouse anti-tyrosine hydroxylase (anti-TH) (1:1000; Diasorin), rabbit anti-dopamine- $\beta$-hydroxylase (DBH) antibodies (1:1000; Diasorin), rabbit anti-TGF- $\beta_{1}$ (1:1000; Chemicon, Temecula, CA), chicken anti-GDNF (1:2000; Chemicon), or rabbit anti-aFGF (1: 1000; Chemicon) in PBS-T. After washing in PBS-T, sections for DBH, TGF- $\beta_{1}$, and aFGF immunohistochemistry were incubated for $1 \mathrm{hr}$ with biotinylated anti-rabbit antibody (1:200; Chemicon), those for GDNF immunohistochemistry were incubated with biotinylated anti-chicken antibody (1:200; Chemicon), and those sections for TH immunohistochemistry were incubated with biotinylated anti-mouse antibody (1:200; Diasorin). Then, all sections were incubated with the ABC kit (1:100; Vector Laboratories) for $1 \mathrm{hr}$, and specifically bound antibody were revealed by using 3.3'-diaminobencidine tetrahydrochloride (DAB; Sigma, St. Louis, MO) as chromogen and $0.01 \%$ hydrogen peroxide. Negative control sections were incubated in the same solutions for the same incubation times as the other brain sections, with the exception that the primary antibody solution was replaced by a PBS-T solution containing $1 \%$ goat serum without the primary antibody. Sections were washed in PBS and mounted on glass slides and coverslipped with DPX.

For immunofluorescence, after quenching and blocking, sections were incubated overnight with monoclonal mouse anti-TH (1:1000; Diasorin) and rabbit anti-DBH antibodies (1:1000; Diasorin) in PBS-T. After washing in PBS-T, sections were incubated for $1 \mathrm{hr}$ with biotinylated anti-rabbit antibody (1:200; Chemicon), and then they were incubated for $2 \mathrm{hr}$ with goat cyanine-2-streptoavidin (green color; 1:1000) and goat cyanine-5-anti-mouse antibody (red color; 1:200). Finally, sections were mounted on glass slides and coverslipped with glycerol and PB (1:1).

Stereological methods and density of striatal TH+ innervation. Volumet- 
ric measurements were done by applying the principle of Cavalieri, using photo sections (Lagares and Avendaño, 1999). Every five coronal sections (50 $\mu \mathrm{m}$ width, $\left.{ }^{-} t=200 \mu \mathrm{m}\right)$ of the Zuckerkandl's organ, adrenal medulla, or the striatal tissue were randomly sampled by using a reticle of hitting points where the area associated with each sampling point was $0.11 \mathrm{~mm}^{3}$ $(\mathrm{a}(\mathrm{p}))$. The estimate of the volume was calculated as $\wedge V={ }^{-} t$. a(p). $\Sigma \mathrm{Pi}$, where $\Sigma \mathrm{Pi}=$ total number of hitting points. The coefficient of error $(\mathrm{CE})$ was calculated according to a formula that takes into account the shape of the organ (e.g., 4.1 for a fusiform organ such as the Zuckerkandl's paraganglion; Gundersen and Jensen, 1987). The number of chromaffin cells was calculated applying the physical disector method (Sterio, 1984). For this procedure, six systematically chosen pairs of adjacent sections $(t=50 \mu \mathrm{m})$ were used. Four disector frames were used for every section, and the area of the disector frame covered 16,104 $\mu \mathrm{m}^{2}$ (a(ret)). The estimated disector volume or $\Sigma \wedge V$ (dis) was calculated as $\Sigma \wedge V($ dis $)=$ number of disectors. ${ }^{-} t$. a(ret). The estimate of the number of cells $(N)$ was calculated as $N=\left(\Sigma \mathrm{Q}^{-} \cdot \wedge V(\right.$ ref $\left.)\right) / \Sigma \wedge V($ dis $)$, where $\Sigma \mathrm{Q}^{-}$was the total number of cells counted in all the disectors, and $V$ (ref) was the estimate of the volume of the chromaffin tissue (in the paraganglion, adrenal medulla, or grafted striatum), as measured by the principle of Cavalieri.

The optical density of striatal $\mathrm{TH}+$ innervation was measured at five different rostrocaudal levels corresponding to approximately $+1.5,+1$, $+0.5,-0.5$, and $-1 \mathrm{~mm}$ relative to bregma (Paxinos and Watson, 1997). Images from coronal sections of ipsilateral and contralateral striata were taken with a high-resolution digital camera from a microscope equipped with a natural density filter to give constant illumination throughout the specimen. The digitalized images were analyzed using Scion Corp. (Frederick, MD) Image for the personal computer, four subdivisions per section being assessed (dorsal, medial, lateral, and ventral regions of dorsal striata), avoiding TH+-transplanted cells in grafted striata. Optical density readings were corrected for background staining (the corpus callosum, a nondopaminergic region of the tissue). To avoid differences in staining intensity between individual animals, all values are expressed as a percentage of the intact contralateral striatum.

HPLC. Four rats per group were killed by decapitation at 5 months after sham (sham-grafted and control groups) or chromaffin cell grafting. The brains were quickly removed and placed on ice, and the left striata was immediately dissected and weighed. The dissected tissue was then chopped into pieces, mixed, and divided equally into two halves (with similar weight) and frozen at $-80^{\circ} \mathrm{C}$ separately (one part for HPLC measurements, the other for GDNF and TGF- $\beta_{1}$ ELISA). Later, tissue samples were homogeneized in $0.5 \mathrm{ml}$ of an ice-cold solution containing (in $\mathrm{M}$ ): $0.4 \mathrm{HClO}_{4}, 0.5$ sodium acetate, and 0.5 acetic acid, and centrifuged at $27,000 \mathrm{rpm}$ for $60 \mathrm{~min}$ at $4^{\circ} \mathrm{C}$. The supernatants were decanted and filtered through a $0.45 \mu \mathrm{m}$ filter (Sartorius), and frozen at $-80^{\circ} \mathrm{C}$ until HPLC assay. The electrochemical performance was based essentially on the method described by Saito et al. (1992). Aliquots (10 $\mu \mathrm{l})$ of each sample were injected directly into the HPLC system (System Gold; Beckman Instruments, Fullerton, CA), consisting of a solvent delivery pump with a pulse-dampener, an automatic sample injector (Carnegie Medicine), and an analytical C18 reverse-phase column (Ultrasphere 3 $\mu \mathrm{m}$ particle size; $75 \times 4.6 \mathrm{~mm}$ inner diameter; Beckman). The ESA model 5100 A Coulochem electrochemical detection system consisted of a model 5021 conditioning cell (detector setting, $+400 \mathrm{mV}$ ) followed in sequence by a model 5011 dual electrode analytical cell (cell 1, $+100 \mathrm{mV}$; cell 2, $-260 \mathrm{mV})$. The output signal from the final electrode was amplified by a 5100 A controller and relayed to an integrator (model 106; Beckman). The detection limit of the system was $0.1 \mathrm{pg} / \mu \mathrm{l}$. The mobile phase for the separation of catecholamines and their metabolites was a mixture of $0.075 \mathrm{M} \mathrm{Na}_{2} \mathrm{HPO}_{4}, 1.2 \mathrm{mM}$ sodium heptanosulfonate, 0.097 $\mathrm{mM}$ EDTA, and $8 \%$ methanol $(\mathrm{v} / \mathrm{v})$ adjusted to $\mathrm{pH} 3.6$. The buffer solution was filtered through a $0.45 \mu \mathrm{m}$ membrane filter and degassed. The flow rate was set to $1.7 \mathrm{ml} / \mathrm{min}$, and pressure was $\sim 2000 \mathrm{psi}$. The mobile phase was recycled for 2 weeks of continuous use before being replaced with fresh solution. The entire chromatographic system was run at ambient temperature. Peaks of biogenic amines and metabolites were identified by comparing the retention time of each peak in the sample solution with that in the standard solution. Dihydroxybenzylamine (DHBA) was used as internal standard for extraction variability, being added to the HPLC samples just before homogenization. The program System Gold 2.01 (Beckman) was used to calculate monoamines levels in each sample. The intrastriatal contents of DA, 3,4-dihydroxyphenylacetic acid (DOPAC), and homovanillic acid (HVA) were quantified (Espejo and Miñano, 2001). Dopamine turnover was estimated by the
DOPAC-DA ratio. Neurochemical data were compared by using nonparametric Kruskal-Wallis tests followed by post hoc Mann-Whitney $U$ tests.

Determination of neurotrophic factors by ELISA. For determination of tissue GDNF and TGF- $\beta_{1}$ proteins, tissue from left striata were sonicated in a homogenization buffer containing $150 \mathrm{~mm} \mathrm{NaCl}, 50 \mathrm{~mm}$ HEPES, $1 \mathrm{~mm}$ phenylmethylsulfonyl fluoride, $0.6 \mu \mathrm{m}$ leupeptin, and $1 \%$ Triton X-100, pH 7.4, at a tissue concentration of $50 \mathrm{mg} / \mathrm{ml}$ (wet weight per volume). Tissue levels of GDNF and TGF- $\beta_{1}$ were determined from tissue homogenates by ELISA using commercial kits, according to supplier's recommendations (G1230, G3520; Promega, Madison, WI). The results were compared by using nonparametric Kruskal-Wallis test followed by post hoc Mann-Whitney $U$ tests.

\section{RESULTS}

\section{Induction of parkinsonism}

Rats were rendered hemiparkinsonian by injecting 6-hydroxydopamine, a toxin that destroys dopaminergic neurons, into the left substantia nigra. Those animals that showed a strong ipsilateral rotational behavior after the administration of amphetamine ( $>420$ turns per hour), indicative of the destruction of $>85 \%$ of the dopaminergic neurons in the substantia nigra (Fornaguera et al., 1994), were selected for grafting. These animals presented an overt hemiparkinsonian syndrome characterized by drug-induced turning, forepaw use asymmetry, and sensorimotor neglect.

\section{Structure of the Zuckerkandl's organ, adrenal medulla, and grafts}

Hemiparkinsonian rats were grafted with aggregates of extraadrenal or adrenal cells $7 \mathrm{~d}$ after the amphetamine test. Cell aggregates instead of dispersed cells were used because it is known that the viability of grafted cells improves with the use of pieces of tissue (Björklund et al., 1980; Espejo et al., 1998; Luquin et al., 1999). Grafts were aimed at the dorsal striatum. To discern the number of grafted chromaffin cells per rat, stereological measurements were made. Thus, the estimate of the volume of the Zuckerkandl's organ $(n=5)$ was $9.5 \pm 1.1 \mathrm{~mm}^{3}$ (mean \pm SEM; mean $\overline{C E}=0.17$ ), and the estimate of the volume of chromaffin tissue inside the organ was $2.1 \pm 0.3 \mathrm{~mm}^{3}$ ( $22 \%$ of the organ; mean $\overline{\mathrm{C}} \mathrm{E}=0.19$ ). The estimate of the number of chromaffin cells, as measured by the physical disector method, was $45,500 \pm 512$ cells (mean $\bar{C} E=0.15$ ). Because the mean volume of the pieces used for transplantation was $0.75 \pm 0.1 \mathrm{~mm}^{3}$, and assuming the same percentage volume of chromaffin tissue in the randomly chosen pieces as that in the organ $\left(22 \%, 0.16 \mathrm{~mm}^{3}\right)$, the estimated number of grafted chromaffin cells was $3466 \pm 213$ cells per graft. Regarding the adrenal gland, the estimate of the volume of the adrenal medulla $(n=5)$ was $8.2 \pm 1.2 \mathrm{~mm}^{3}$ (mean $\pm \mathrm{SEM}$; mean $\overline{\mathrm{C}} \mathrm{E}=0.18$ ), and the estimate of the number of adrenal chromaffin cells, as measured by the physical disector method, was 219,806 $\pm 21,847$ cells (mean $\overline{\mathrm{C}} \mathrm{E}=0.14$ ). Because the mean volume of the pieces used for transplantation was $0.74 \pm 0.2 \mathrm{~mm}^{3}$, the estimated number of grafted adrenal chromaffin cells was $19,836 \pm 1963$ cells per graft.

Neurotransmitter phenotypic expression in chromaffin cells of pieces of paraganglia and adrenal medulla used for grafting was studied by staining for immunofluorescence to $\mathrm{TH}$, the dopamine synthesizing enzyme, and DBH, the noradrenaline synthesizing enzyme. As revealed by confocal fluorescent microscopy of sections taken from the paraganglia used for transplantation, the Zuckerkandl's organ contained rounded or polymorphic $\mathrm{TH}+$ / $\mathrm{DBH}+$ chromaffin cells $(20-30 \mu \mathrm{m}$ in diameter $)$ and mesenchyma (Fig. 1), and the adrenal medulla contained many rounded $\mathrm{TH}+/ \mathrm{DBH}+$ chromaffin cells $(15-25 \mu \mathrm{m}$ in diameter) (Fig. $1 d)$. 

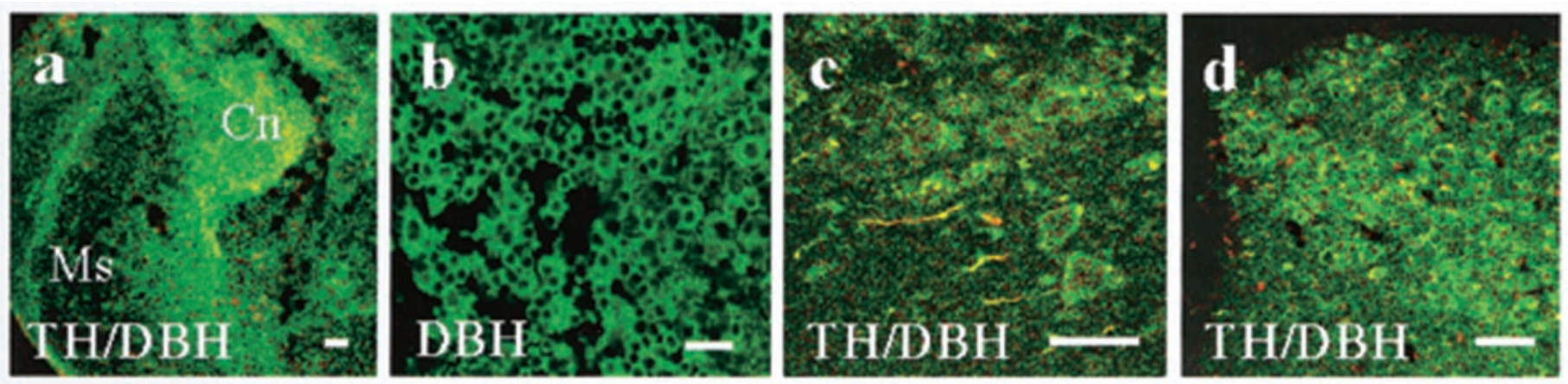

Figure 1. Morphological features of the Zuckerkandl's organ $(a-c)$ and adrenal medulla $(d)$. $a$, Coronal section of the Zuckerkandl's organ used for transplantation, without enzymatic treatment, after double labeling for TH (red) and DBH (green). Confocal fluorescent micrograph shows dispersed cell groups and cell nests $(C n)$ of noradrenergic chromaffin cells $(\mathrm{TH}+/ \mathrm{DBH}+$; yellow-green) surrounded by mesenchyma $(M s)$. $b$, Higher magnification of a cell nest labeled for DBH showing many DBH+ rounded chromaffin cells of 20-30 $\mu \mathrm{m}$ in diameter (green). c, Higher magnification of chromaffin cells with green and yellow patches in the cytoplasm indicative of the presence of DBH and TH-DBH, respectively, and hence norepinephrine. $d$, Piece of an adrenal medulla used for transplantation, without enzymatic treatment, after double labeling for TH and DBH immunofluorescence. Confocal fluorescent micrograph shows many rounded chromaffin cells (15-25 $\mu \mathrm{m}$ in diameter) with green and yellow patches in the cytoplasm, indicative of the presence of DBH and TH-DBH. Scale bars: $a, 200 \mu \mathrm{m} ; b, d, 100 \mu \mathrm{m} ; c, 50 \mu \mathrm{m}$.

In the Zuckerkandl's organ, $\mathrm{TH}+/ \mathrm{DBH}+$ chromaffin cells were found to be associated in cell clusters and bigger "cell nests" (Fig. $1 a$, yellow-green color), in accordance with other authors (Testut and Latarjet, 1978; Bohn et al., 1982), and dopaminergic or $\mathrm{TH}+/ \mathrm{DBH}-$ cells were not observed (absence of red fluorescent cells). Fluorescent microscopy hence confirmed that the Zuckerkandl's organ belongs to the type of extra-adrenal chromaffin paraganglia with mesenchyma (Testut and Latarjet, 1978), and that its chromaffin cells are not dopaminergics, but noradrenergics and/or adrenergics.

Progressive amelioration of parkinsonian deficits after grafts of the extra-adrenal Zuckerkandl's organ, and transient recovery after adrenal cell transplants

One month after grafting, drug-induced turning was reduced by $36 \%$ (Zuckerkandl group, nonsignificant) and 65\% (adrenal group, $p<0.05$ ), and the right forepaw use ratio was not significantly different from controls in both grafted groups. Sensorimotor deficits were significantly ameliorated in both groups (whisker test, 77\%, Zuckerkandl; 72.2\% adrenal; odor test, 60\%, Zuckerkandl; 75\%, adrenal) versus sham-grafted parkinsonian rats ( $p<$ $0.01)$. However, although behavioral recovery was transient in rats grafted with adrenal cells, functional recovery was sustained and gradually enhanced over time in the Zuckerkandl group, as observed in Figure 2. Thus, the adrenal group showed a significant recovery in motor and sensorimotor deficits up to the second month after grafting, but thereafter the salutary effects wore off, the rats' behavior being similar to that found in sham-grafted parkinsonian rats that did not otherwise show any significant amelioration. Regarding the Zuckerkandl group, 5 months after transplantation, drug-induced turning was significantly ameliorated by $80 \%(p<0.01)$, right forepaw use ratio was $42 \%(t=$ $14.2 ; p<0.01$ vs sham-grafted and adrenal groups without significant differences with control nonparkinsonian rats), and sensorimotor orientation fully recovered (whisker, 91.2\%; odor, 94\% vs sham-grafted rats, without significant differences with controls). Noteworthy, the degree of functional recovery depended on the intensity of the parkinsonian syndrome, as measured through the number of drug-induced turnings. Thus, motor asymmetry was completely abolished in 5 of 12 rats, those with a number of rotations $<650 / \mathrm{hr}$ after nigra lesion.

\section{Striatal reinnervation and long survival of grafted extra-adrenal cells of the Zuckerkandl's organ}

At 5 months after grafting, different degrees of TH-positive reinnervation of the grafted striatum were observed in rats with Zuckerkandl's organ grafts (Fig. 3a,b). Thus, stereological methods revealed that the mean percentage of volume of reinnervation was $68.3 \%$ (26 $\pm 0.3 \mathrm{~mm}^{3}$ of reinnervated area of a mean dorsal striatal volume of $38.1 \pm 0.4 \mathrm{~mm}^{3}$; mean $\overline{\mathrm{C}} \mathrm{E}=0.12$ ). Densitometry measurements also showed a significant increase in striatal $\mathrm{TH}$ innervation in the grafted striatum, although to a lesser degree, from $12.8 \pm 1 \%$ of normal in denervated sham-grafted striata (Fig. $3 e$ ) to $49.9 \pm 12 \%$ of normal in grafted animals, as shown in Table 1. Grafts were stained with TH and DBH antisera or thionin, being located in the dorsal striatum presenting a fusiform or oval morphology (Fig. 3). Immunohistochemistry staining revealed the presence of $\mathrm{TH}+$ and $\mathrm{DBH}+$ chromaffin cells inside grafts, many of them with long neuritic processes emerging from the soma (Fig. $3 c$ ). Confocal fluorescent microscopy also showed the presence of $\mathrm{DBH}+$ cells and neuritic processes running out the graft into the surrounding striatum (Fig. $3 d$ ). No grafted cells were observed out of the grafting site. The mean number of chromaffin cells inside the grafts was $461 \pm$ 56 cells at this stage, and considering that grafted paraganglion pieces contained $3466 \pm 213$ chromaffin cells, this indicates that $\sim 13.3 \%$ of chromaffin cells survived the grafting trauma. The number of surviving transplanted cells in five grafted rats as measured through stereology is shown in Table 1. In contrast, at 5 months after grafting, brain sections with adrenal grafts stained for immunohistochemistry to $\mathrm{TH}$ revealed the presence of grafts with a necrotic appearance without surviving $\mathrm{TH}+$ chromaffin cells, and lack of $\mathrm{TH}+$ positivity of the host striatum, except for the presence of a $\mathrm{TH}+$ halo in the immediate neighborhood of the graft and, in some cases, a small $\mathrm{TH}+$ striatal area at the border of the left ventricle, as shown in Figure $3 f$.

\section{Grafted chromaffin cells of the Zuckerkandl's organ express and release GDNF and TGF- $\boldsymbol{\beta}_{1}$}

To detect if grafted extra-adrenal chromaffin cells expressed neurotrophic factors, striatal sections containing grafts $(n=3)$ were stained for immunoreactivity to the neurotrophic factors 

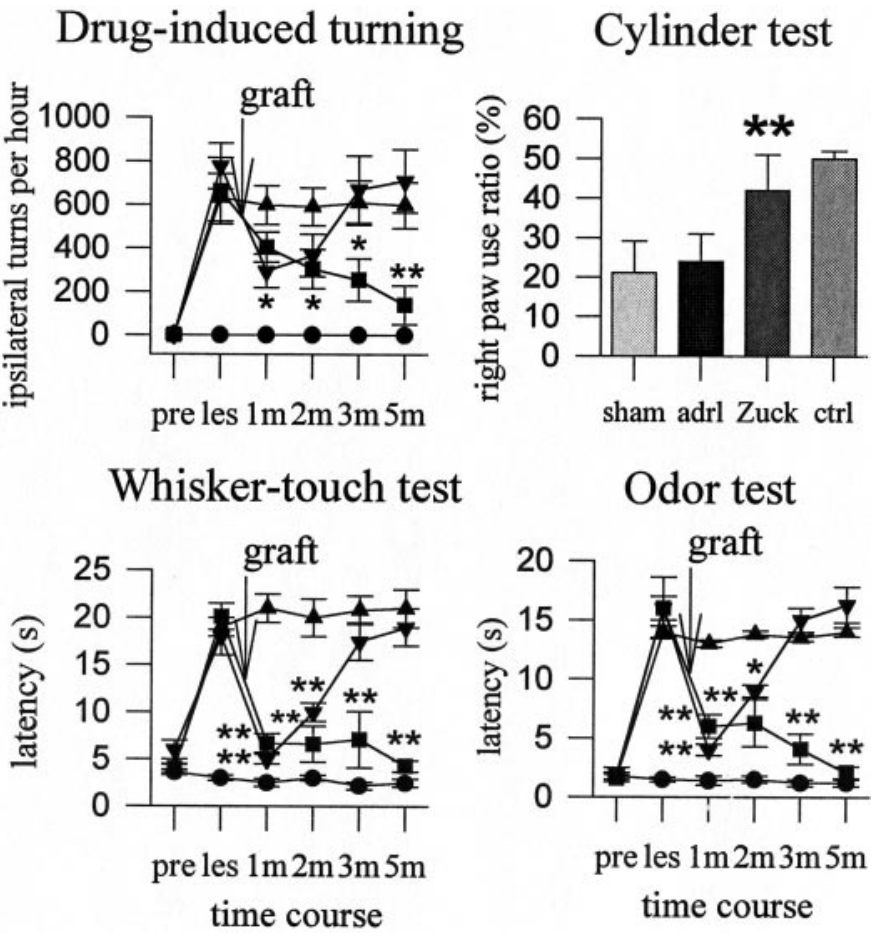

Figure 2. Time course of drug-induced turning, right forepaw use (cylinder test), and sensorimotor orientation (whisker-touch and odor tests), after grafts of the Zuckerkandl's organ and adrenal tissue. Groups: control (nonparkinsonian rats); $\mathbf{0}$, 6-OHDA-induced lesion and Zuckerkandl's or-

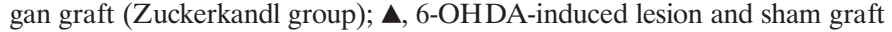

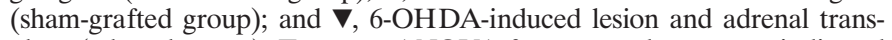
plant (adrenal group). Two-way ANOVA for repeated measures indicated significant group $(3,41 \mathrm{df})$ and interaction effects $(15,210 \mathrm{df})$ for druginduced turning (group, $F=12.4$; interaction, $F=7.3 ; p<0.001$ ), whiskertouch latency (group, $F=133.2$; interaction, $F=36.7 ; p<0.001$ ), and odor latency (group, $F=80.8$; interaction, $F=26.6 ; p<0.001$ ). Maximum latency in sensorimotor tests, $25 \mathrm{sec}$. Mean \pm SEM. ${ }^{*} p<0.05$; $* * p<0.01$ versus sham-grafted rats (Newman-Keuls test, or Student's $t$ test in the cylinder test). pre, Before lesion; les, 2 weeks after lesion; $1 m, 2 m, 3 m, 5 m, 1,2,3$ and 5 months after extra-adrenal, adrenal, or sham grafting, respectively; ctrl, control group; adrl, adrenal group; Zuck, Zuckerkandl group; sham, shamgrafted group. Grafts were implanted 2 weeks after nigra lesion (arrow). The cylinder test corresponds to values 5 months after grafting.

GDNF, TGF- $\beta_{1}$, and aFGF. Grafted paraganglionic cells presenting GDNF and TGF- $\beta_{1}$ positivity, but not aFGF, were observed as shown in Figure 4. This indicates that extra-adrenal chromaffin cells expressed the neurotrophic factors GDNF and TGF- $\beta_{1}$ after grafting in vivo. The presence of these neurotrophic factors in host striatal tissue $(n=4)$ was then discerned by means of ELISA. Detectable levels of GDNF and TGF- $\beta_{1}$ proteins were measured in the left striatum of grafted parkinsonian rats, as shown in Table 2. GDNF and TGF- $\beta_{1}$ protein levels were threefold and fivefold higher, respectively, in the striatum of grafted rats in comparison with that of sham-grafted rats $(U=0 ; p<0.05)$. These findings indicate that extra-adrenal chromaffin cells chronically released these neurotrophic factors into the host striatum after grafting.

\section{Dopamine neurotransmission is improved in denervated striatum after grafts of the Zuckerkandl's organ}

To establish whether functional recovery in rats was linked to enhanced levels of intrastriatal dopamine, postmortem contents of this amine and their metabolites DOPAC and HVA
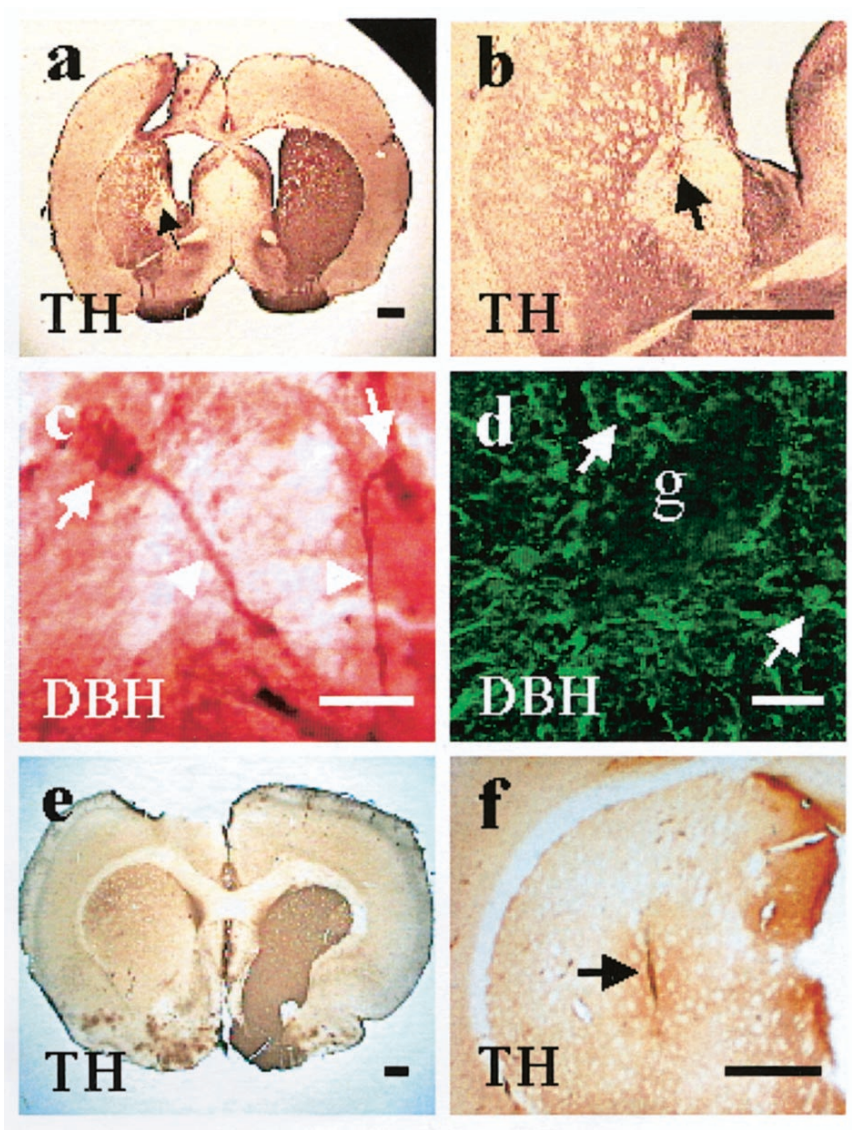

Figure 3. Morphological features of 5-month-old transplants of the Zuckerkandl's organ $(a-d)$, as well as striatal appearance 5 months after sham-grafting $(e)$ or adrenal cell transplants $(f) \cdot a, b$, Coronal sections of the striatum grafted with extra-adrenal cells of the Zuckerkandl's organ where a TH-positive transplant (arrow) and a broad TH+ reinnervated area in the host left striatum (brown) can be clearly observed. $c$, Higher magnification of the transplant labeled for $\mathrm{DBH}$ where $\mathrm{DBH}+$ chromaffin cells (arrows) with long neuritic processes (arrowheads) are observed. $d$, Confocal fluorescent micrographs of the graft revealing the presence of $\mathrm{DBH}+$ cells (green, arrows) and many neuritic processes running out of the graft. $e$, Coronal section of a sham-grafted striatum showing the nearly absent $\mathrm{TH}$ positivity in the left denervated striatum. $f$, Coronal section through the brain striatum with an adrenal medullary transplant, where a necrotic graft can be observed (arrow), as well as lack of striatal $\mathrm{TH}$ positivity except for a halo of TH positivity surrounding the graft, and a small $\mathrm{TH}+$ area at the border of the left ventricle. $g$, Graft. Scale bars: $a, b, e, f, 1 \mathrm{~mm} ; d, 100 \mu \mathrm{m} ; c, 50 \mu \mathrm{m}$.

were measured by HPLC in left striata of four rats per group (Table 3). Denervated striata of sham-grafted and adrenal groups showed very low levels of DA $(-82,-75.6 \%$, respectively, vs normal striata) and strongly enhanced levels of DOPAC and HVA, DA metabolites (sham = DOPAC, $+361.9 \%$; HVA, $+318.3 \%$; adrenal = DOPAC, $+332.4 \%$; HVA, $+330.3 \%)$. Besides, DA "turnover" was strongly enhanced (sham, $+2,541 \%$; adrenal, $+1,712 \%$ ). In this context, it is supposed that the increases in DOPAC and HVA levels and DA "turnover" reflect enhanced dopamine release and metabolism in the surviving DA neurons (Robinson and Whishaw, 1988; Sarre et al., 1994; Wachtel and Abercrombie, 1994). After extra-adrenal grafting, the striatal content of dopamine was significantly enhanced $(+140.7 \%)$, and the levels of DOPAC and HVA were reduced (DOPAC, $-40.2 \%$; HVA, $-47.5 \%$ ) versus sham-grafted denervated striata. The DA 
Table 1. Densitometry measurement for TH+ signal in the left striatum of sham-grafted animals and rats with extra-adrenal cell grafts, along with the estimate of the number of surviving extra-adrenal cells at 5 months after grafting

Individual values

Mean \pm SEM

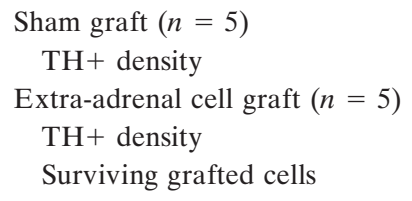

$\begin{array}{cc}13.7 & 11.2 \\ 27.3 & 66.7 \\ 381 & 489\end{array}$

$\begin{array}{cc}1.2 & 9.7 \\ & \\ 6.7 & 89.1 \\ 9 & 655\end{array}$

$\begin{array}{ccc} & & \text { Mean } \pm \text { SEM } \\ 14.4 & 15.2 & 12.8 \pm 1 \\ 34.1 & 32.3 & 49.9 \pm 12 \\ 328 & 452 & 461 \pm 56\end{array}$

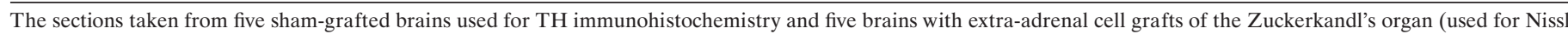

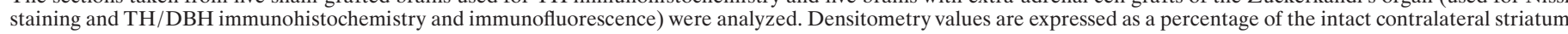
in every rat. The estimate of the number of surviving chromaffin cells was calculated by using estereological methods.

"turnover" was also reduced $(-75 \%)$, indicating an improvement of DA neurotransmission and metabolism in grafted striata. In comparison with dopaminergic levels within nondenervated normal striata of control rats, the Zuckerkandl's organ grafts induced DA levels to be increased by $43 \%$ of normal at 5 months after grafting (a quite similar percentage value to that obtained for $\mathrm{TH}+$ density in grafted striata).

\section{DISCUSSION}

\section{Long-term functional recovery after extra-adrenal cell grafts of the Zuckerkandl's organ versus transient recovery after adrenal cell grafts}

Remarkably, cell aggregates grafts of the extra-adrenal Zuckerkandl's organ induced a progressive and sustained functional recovery in parkinsonian rats. These beneficial effects were related to the survival of $13.3 \%$ of grafted extra-adrenal chromaffin cells, a finding otherwise quite similar to the survival rate of grafted mesencephalic dopamine neurons (3-20\%; Brundin et al., 2000). This indicates that those grafted chromaffin cells that survived the grafting trauma then survived for a long period, making them suitable for transplantation. Although the survival rate can be considered as low, representing a potential limitation for the therapeutic value of these grafts, it is always possible either to increase the amount of implanted tissue or, as revealed by studies with other grafting cells such as neural ones, to treat the grafting tissue before transplantation with antioxidants such as lazaroids or neurotrophic factors to increase the survival rate of grafted cells (Brundin et al., 2000). These approaches could be applied to Zuckerkandl's organ grafts, a fact that requires further investigation in animal Parkinson's models. However, of note is that the long-surviving grafted cells induced an important functional recovery, together with a significant enhancement of $\mathrm{TH}+$ density in the host striatum (indicative of dopaminergic reinnervation), and a reliable increase in the intrastriatal dopaminergic

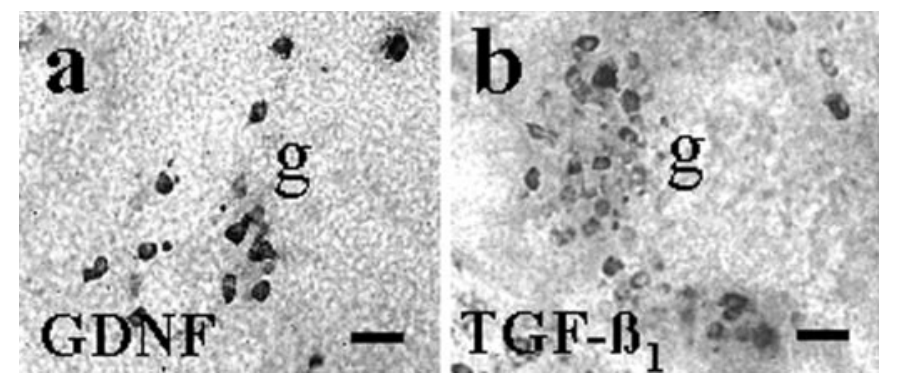

Figure 4. Immunohistochemistry for GDNF and TGF- $\beta_{1}$ in transplants of the Zuckerkandl's organ at 5 months after grafting, showing the presence of GDNF-positive $(a)$ and TGF- $\beta_{1}$-positive chromaffin cells $(b)$. $g$, Graft. Scale bars, $100 \mu \mathrm{m}$. content, as measured through HPLC. This latter fact surely led to functional improvements of drug-induced turning, forepaw use, and sensorimotor orientation in parkinsonian rats, which are dependent on the recovery of the dopaminergic tone of dorsal striatum (Björklund et al., 1980; Brundin et al., 1987). An improvement of dopamine metabolism was also revealed by HPLC through the reduction of dopamine "turnover," which was found to be highly enhanced in denervated striata, surely as a reactive response of surviving nigra neurons (Robinson and Whishaw, 1988; Sarre et al., 1994; Wachtel and Abercrombie, 1994). The increase of striatal dopaminergic content after grafting cannot be explained by dopamine cell release, because grafted cells were not dopaminergics ( $\mathrm{TH}+/ \mathrm{DBH}-$ cells), and it is known that only minute amounts of dopamine can be released from $\mathrm{TH}+/ \mathrm{DBH}+$ adrenal and extra-adrenal chromaffin cells, as reported by other authors (Lyon et al., 1987; Missale et al., 1988; Pupilli et al., 1994). The findings indicate that the improved dopaminergic tone after grafting can be better accounted for by striatal regeneration because of sprouting of spared dopaminergic fibers, as indicated by the broad $\mathrm{TH}+$ area and the enhanced $\mathrm{TH}+$ density in the grafted striata. This is consistent with the time course of functional recovery, which developed progressively over the 5 months after the lesion, as seen in motor and sensorimotor tests. A possible participation on sprouting of the neuritic processes arising from grafted extra-adrenal cells cannot be discarded, although its number was limited and cannot account for all the gain of diffuse (and distant to the graft) TH staining in the striatum.

In contrast, adrenal medullary transplants only induced a transiently behavioral recovery, and the histological study revealed that, at 5 months after grafting, grafts presented a degenerate appearance, and there were no surviving grafted cells. This finding is in accordance with previous studies demonstrating that adrenal chromaffin cells present a poor survival in the brain and induce a transient amelioration in parkinsonian rats (Yurek and

\begin{tabular}{|c|c|c|}
\hline Group & GDNF & TGF- $\beta 1$ \\
\hline Control $(n=4)$ & $0.03 \pm 0.02$ & $0.04 \pm 0.01$ \\
\hline Sham-grafted $(n=4)$ & $0.06 \pm 0.02$ & $0.05 \pm 0.02$ \\
\hline Adrenal $(n=4)$ & $0.04 \pm 0.02$ & $0.06 \pm 0.02$ \\
\hline Zuckerkandl $(n=4)$ & $0.19 \pm 0.08^{*}$ & $0.24 \pm 0.09^{*}$ \\
\hline
\end{tabular}

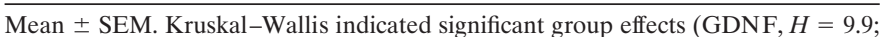
TGF- $\beta 1, H=9.4 ; p<0.01$ ).

${ }^{*} p<0.05$ versus the other three groups (Mann-Whitney $U$ test). 
Table 3. Levels of dopamine, DOPAC, and HVA (micrograms per gram wet weight tissue) and DOPAC/DA ratio in punches from left striatum in controls, sham-grafted animals, and rats with grafts of adrenal cells or extra-adrenal cells of the Zuckerkandl's organ (at 5 months after grafting)

\begin{tabular}{lllll} 
Group & DA & DOPAC & DOPAC/DA & HVA \\
\hline Control $(n=4)$ & $6.02 \pm 0.5$ & $1.05 \pm 0.1$ & $0.17 \pm 0.01$ & $1.42 \pm 0.1$ \\
Sham-grafted $(n=4)$ & $1.08 \pm 0.2^{* * *}$ & $4.85 \pm 0.5^{* * *}$ & $4.49 \pm 0.7^{* * *}$ & $3.94 \pm 0.6^{* * *}$ \\
Adrenal $(n=4)$ & $1.47 \pm 0.2^{* * *}$ & $4.54 \pm 0.3^{* * *}$ & $3.08 \pm 0.6^{* * *}$ & $6.11 \pm 0.7^{* * *}$ \\
Zuckerkandl $(n=4)$ & $2.6 \pm 0.3^{* * *}$ & $2.91 \pm 0.3^{* * * *}$ & $1.12 \pm 0.1^{* * * *}$
\end{tabular}

Mean \pm SEM. Kruskal-Wallis test indicated significant group effects (DA and DOPAC, $H=9.8$; ratio, $H=10.1$; HVA, $H=9.9 ; p<0.01$ ).

${ }^{*} p<0.05$ versus sham-grafted and adrenal groups; ${ }^{* *} p<0.05 ; * * * p<0.01$ versus control group (Mann-Whitney $U$ test).

Sladek, 1990; Bresjenac et al., 1997). Furthermore, the dopaminergic content of grafted striata remained very low, and there were no signs of striatal reinnervation, except for a halo of $\mathrm{TH}+$ fibers immediately around the graft. This perigraft sprouting has already been observed after adrenal medullary grafts implanted in the striatum (Bohn et al., 1987; Bankiewicz et al., 1994; Bresjenac et al., 1997), and it has been demonstrated to be attributable to infiltration of microglia and macrophages that exert a limited trophic action that persists for many months after injury or grafting (Batchelor et al., 1999). In this context, in dead parkinsonian patients with 3 - to 40 -month-old adrenal medullary grafts, autopsy revealed that there was often a perigraft dopaminergic sprouting response without surviving adrenal cells inside the graft (Hirsch et al., 1990; Kordower et al., 1991). The data of the present study hence indicate that transient recovery after adrenal transplants would be accounted for by the beneficial action of adrenal chromaffin cells before cell death and graft degeneration.

\section{Grafted extra-adrenal cells of the Zuckerkandl's organ express and release GDNF and TGF- $\beta_{1}$, and induce striatal regeneration}

It is well known that intrinsic dopaminergic reinnervation of the denervated striatum is a constant feature after grafting chromaffin cells (Freed et al., 1981; Bohn et al., 1987; Espejo et al., 1998; Dunnett and Björklund, 1999; Luquin et al., 1999). The broad $\mathrm{TH}+$ reinnervation measured in striata with extra-adrenal chromaffin cells suggests that grafted cells exerted a trophic action on the denervated striatum leading to sprouting of host dopaminergic fibers. In this context, the mechanisms underlying the trophic action of chromaffin cells of the adrenal lineage is poorly understood, but it has been recently shown that adrenal medullary cells contain and release trophic factors such as GDNF and TGF- $\beta_{1}$, both in vitro and in vivo (Unsicker and Krieglstein, 1995, 1996; O'Connor, 1999; Combs et al., 2000). GDNF is an extraordinarily potent neurotrophic factor (active at picomolar concentrations) which, when delivered by injection or via transplanted cells or viruses, protects dopaminergic neurons in animal models of Parkinson's disease (Lin et al., 1993; Beck et al., 1995; Tomac et al., 1995; Tseng et al., 1997; Gash et al., 1998; Hagg, 1998; Krieglstein et al., 1998; Rosenblad et al., 1999; Kirik et al., 2000; Aebischer and Ridet, 2001). TGF- $\beta_{1}$ is also known to protect dopaminergic neurons when delivered in vitro (Unsicker et al., 1996) and, interestingly, TGF- $\beta_{1}$ is an important cofactor that potentiates the neurotrophic actions of GDNF in vitro and in vivo (Krieglstein et al., 1998; Schober et al., 1999). The immunohistochemical data of the present study revealed that grafted extra-adrenal chromaffin cells also expressed GDNF and TGF- $\beta_{1}$, and significant levels of these neurotrophic factors were detected in the striatal tissue as measured by ELISA, strongly suggesting that extra-adrenal chromaffin cells chronically released them after grafting in vivo. Hence, the well known neurorestorative action of GDNF on dopaminergic neurons, together with a TGF- $\beta_{1}$ induced potentiation of GDNF activity, could account for the striatal reinnervation of the host tissue. Clearly, the main advantage of grafts of the Zuckerkandl's organ appears to be the long survival of extra-adrenal chromaffin cells (in contrast to adrenal chromaffin cells) that allow them to exert a chronic trophic action based on the delivery of GDNF and TGF- $\beta_{1}$, and likely other neuroprotective agents such as neuropeptides and cytokines that are known to be released by chromaffin cells as well (Unsicker, 1993). These findings strongly enhance the potential therapeutic value of the grafts of the Zuckerkandl's organ. Another advantage of grafts of the Zuckerkandl's organ is that there are two paraganglia in humans, hence the surgical resection of one organ would not have significant side effects.

In conclusion, our study has documented that intrabrain grafts of the Zuckerkandl's organ, an extra-adrenal paraganglion without dopaminergic cells, induced progressive and sustained improvement of functional deficits in parkinsonian rats. In contrast, grafts of adrenal chromaffin cells only induced a transient recovery. The beneficial effects of grafts of the Zuckerkandl's organ were related to long survival of grafted cells, striatal reinnervation, enhancement of dopamine levels in the host striatum, and the cell delivery into the host striatum of glial cell line-derived neurotrophic factor and transforming growth factor- $\beta_{1}$. These neurotrophic factors have neurorestorative properties on dopaminergic neurons, which could account for the tissue regeneration. Because more available and less controversial alternative sources for antiparkinsonian therapy need to be developed (Jennings, 2000), this work should stimulate research on the clinical applicability of transplants of the Zuckerkandl's organ in Parkinson's disease.

\section{REFERENCES}

Aebischer P, Ridet J-L (2001) Recombinant proteins for neurodegenerative diseases: the delivery issue. Trends Neurosci 24:533-540.

Ahonen M, Soinila S, Joh TH (1987) Pre- and postnatal development of rat retroperitoneal paraganglia. J Auton Nerv Syst 18:11-120.

Bankiewicz KS, Palmatie M, Plunkett RJ, Cummins A, Oldfield EH (1994) Reversal of hemiparkinsonian syndrome in nonhuman primates by amnion implantation into caudate nucleus. J Neurosurg 81:869-876. Batchelor PE, Liberatore GT, Wong JYF, Porritt MJ, Frerichs F, Donnan GA, Howells DW (1999) Activated macrophages and microglia induce dopaminergic sprouting in the injured striatum and express brainderived neurotrophic factor and glial cell line-derived neurotrophic factor. J Neurosci 19:1708-1716.

Beck KD, Valverde J, Alexi T, Poulsen K, Moffat B, Vandlen RA, Rosenthal A, Hefti F (1995) Mesencephalic dopaminergic neurons protected by GDNF from axotomy-induced degeneration in the adult brain. Nature 373:339-341.

Björklund A, Dunnett SB, Stenevi U, Lewis ME, Iversen SD (1980) Reinnervation of the denervated striatum by substantia nigra transplants: functional consequences as revealed by pharmacological and sensorimotor testing. Brain Res 199:307-333.

Bohn MC, Goldstein M, Black IB (1982) Expression of phenylethano- 
lamine $N$-methyltransferase in rat sympathetic ganglia and extraadrenal chromaffin tissue. Dev Biol 89:299-308.

Bohn MC, Cupit LC, Marciano F, Gash DM (1987) Adrenal medullary grafts enhance recovery of striatal dopaminergic fibers. Science 237:913-916.

Bolam JP, Freund TF, Björklund A, Dunnett SB, Smith AD (1987) Synaptic input and local output of dopaminergic neurons in grafts that functionally reinnervate the host striatum. Exp Brain Res 68:131-146.

Bresjenac M, Sagen J, Seigel G, Paino CL, Kordower J, Gash DM (1997) Xenogenic adrenal medulla graft rejection rather than survival leads to increased rat striatal tyrosine hydroxylase immunoreactivity. J Neuropathol Exp Neurol 56:490-498.

Brundin P, Strecker RE, Londos E, Björklund A (1987) Dopamine neurons grafted unilaterally to the nucleus accumbens affect drug-induced circling and locomotion. Exp Brain Res 69:183-194.

Brundin P, Karlsson J, Emgard M, Kaminski Schierle GS, Hansson O, Petersen A, Castilho RF (2000) Improving the survival of grafted dopaminergic neurons: a review over current approaches. Cell Transpl 9:179-195.

Combs SE, Krieglstein K, Unsicker K (2000) Reduction of endogenous TGF-beta increases proliferation of developing adrenal chromaffin cells in vivo. J Neurosci 59:379-383.

Dunnett SB, Björklund A (1999) Prospects for new restorative and neuroprotective treatments in Parkinson's disease. Nature 399:A32-A39.

Espejo EF, Miñano FJ (2001) Adrenergic hyperactivity and metanephrine excess in the nucleus accumbens after prefrontocortical dopamine depletion. J Neurophysiol 85:1270-1275.

Espejo EF, Montoro RJ, Armengol JA, López-Barneo J (1998) Cellular and functional recovery of parkinsonian rats after intrastriatal transplantation of carotid body cell aggregates. Neuron 20:197-206.

Fornaguera J, Carey RJ, Huston JP, Schwarting RKW (1994) Behavioral asymmetries and recovery in rats with different degrees of unilateral striatal dopamine depletion. Brain Res 664:178-188.

Freed WJ, Morihisa JM, Spoor E, Hoffer BJ, Olson L, Seiger A, Wyatt RJ (1981) Transplanted adrenal chromaffin cells in rat brain reduce lesion-induced rotational behavior. Nature 292:351-352.

Gash DM, Zhang ZM, Gerhardt G (1998) Neuroprotective and neurorestorative properties of GDNF. Ann Neurol (Suppl) 44:G121-S125.

Goetz CG, Stebbins GT, Klawans HL, Holler WC, Grossman RG, Bakay RA, Penn RD (1991) United Parkinson Foundation neurotransplantation registry on adrenal medullary transplants presurgical, and 1-year and 2-year follow-up. Neurology 41:1719-1722.

Gundersen HJG, Jensen EB (1987) The efficiency of systematic sampling in stereology and its prediction. J Microsc 147:229-263.

Hagg T (1998) Neurotrophins prevent death and differentially affect tyrosine hydroxylase of adult rat nigrostriatal neurons in vivo. Exp Neurol 149:183-192.

Hirsch EC, Duyckaerts C, Javoy-Agid F, Hauw JJ, Agid Y (1990) Does adrenal graft enhance recovery of dopaminergic neurons in Parkinson's disease? Ann Neurol 27:676-682.

Jennings C (2000) Is neural cell transplantation ready for the clinic? Nat Med 6:634.

Kirik D, Rosenblad C, Björklund A, Mandel RJ (2000) Long-term rAAV-mediated gene transfer of GDNF in the rat Parkinson's model: intrastriatal but not intranigral transduction promotes functional regeneration in the lesioned nigrostriatal system. J Neurosci generation in

Kordower JH, Cochran E, Penn RD, Goetz CG (1991) Putative chromaffin cell survival and enhanced host-derived TH-fiber innervation following a functional adrenal medulla autograft for Parkinson's disease. Ann Neurol 29:405-412.

Krieglstein K, Henheik P, Farkas L, Jaszai J, Galter D, Krohn K, Unsicker K (1998) Glia cell line-derived neurotrophic factor requires transforming growth factor-beta for exerting its full neurotrophic potential on peripheral and CNS neurons. J Neurosci 18:9822-9834.

Lagares A, Avendaño C (1999) An efficient method to estimate cell number and volume in multiple dorsal root ganglia. Acta Stereol 18:185-195.

Lin LF, Doherty DH, Lile JD, Bektesh S, Collins F (1993) GDNF: a glial cell line-derived neurotrophic factor for midbrain dopaminergic neurons. Science 260:1130-1132.

Luquin MR, Montoro RJ, Guillén J, Saldise L, Insausti R, Del Río J, López-Barneo J (1999) Recovery of chronic parkinsonian monkeys by autotransplants of carotid body cell aggregates into putamen. Neuron 22:743-750.

Lyon RA, Titeler M, Bigornia L, Schneider AS (1987) D2 dopamine receptors on bovine chromaffin cell membranes: identification and characterization by $[3 \mathrm{H}] N$-methylspiperone binding. J Neurochem 48:631-635.
Mandel RJ, Spratt SK, Snyder RO, Leff SE (1997) Midbrain injection of recombinant adeno-associated virus encoding rat glial cell line-derived neurotrophic factor protects nigral neurons in a progressive 6-hydroxydopamine-induced degeneration model of Parkinson's disease in rats. Proc Natl Acad Sci USA 94:14083-14088.

Marshall JF (1979) Somatosensory inattention after dopamine-depleting intracerebral 6-OHDA injections: spontaneous recovery and pharmacological control. Brain Res 177:311-324.

Missale C, Castelleti L, Memo M, Carruba MO, Spano PF (1988) Identification of postsynaptic D1 and D2 dopamine receptors in cardiovascular system. J Cardiovasc Pharmacol 11:643-650.

O'Connor DT (1999) Chromaffin cell mechanisms: understanding catecholamine storage and release. Trends Pharmacol Sci 20:431-432.

Paxinos G, Watson C (1997) The rat brain in stereotaxic coordinates. Sydney: Academic

Pupilli C, Lanzillotti R, Fiorelli G, Selli C, Gomez RA, Carey RM, Serio M, Mannelli M (1994) Dopamine D2 receptors gene expression and binding sites in adrenal medulla and pheochromocytoma. J Clin Endocrinol Metab 79:56-61.

Robinson TE, Whishaw IQ (1988) Normalization of extracellular dopamine in striatum following recovery from a partial unilateral 6-OHDA lesion of the substantia nigra: a microdialysis study in freely moving rats. Brain Res 450:209-224.

Rosenblad C, Kirik D, Devaux B, Moffat B, Phillips HS, Björklund A (1999) Protection and regeneration of nigral dopaminergic neurons by neurturin or GDNF in a partial lesion model of Parkinson's disease after administration into the striatum or the lateral ventricle. Eur J Neurosci 11:1554-1566.

Saito H, Murai S, Abe E, Masuda Y, Itoh T (1992) Rapid and simultaneous assay of monoamine neurotransmission and their metabolites in discrete brain areas of mice by HPLC with coulometric detection. Pharmacol Biochem Behav 42:351-356.

Sarre S, De Klippel N, Herregodts P, Ebinger G, Michotte Y (1994) Biotransformation of locally applied L-dopa in the corpus striatum of the hemi-parkinsonian rat studied with microdialysis. Naunyn Schmiedebergs Arch Pharmacol 350:15-21.

Schober A, Hertel R, Arumae U, Farkas L, Jaszai J, Krieglstein K, Saarma M, Unsicker K (1999) Glial cell line-derived neurotrophic factor rescues target-deprived sympathetic spinal cord neurons but requires transforming growth factor-beta as cofactor in vivo. J Neurosci 19:2008-2015.

Schwarting RKW, Huston JP (1996) The unilateral 6-hydroxydopamine lesion model in behavioral brain research: analysis of functional deficits, recovery and treatments. Prog Neurobiol 50:275-331.

Sterio DC (1984) The unbiased estimation of number and sizes of arbitrary particles using the disector. J Microsc 134:127-136.

Stricker EM, Zigmond MJ (1986) In: The nervous system: neurophysiology (Mountcastle VB, Boom F, Geiger SR, eds), pp 677-700. Baltimore: Waverly.

Testut L, Latarjet A (1978) Tratado de anatomía humana. Barcelona: Salvat.

Tomac A, Lindqvist E, Lin LF, Ogren SO, Young D, Hoffer BJ, Olson L (1995) Protection and repair of the nigrostriatal dopaminergic system by GDNF in vivo. Nature 373:335-339.

Tseng JL, Baetge EE, Zurn AD, Aebisher P (1997) GDNF reduces drug-induced rotational behavior after medial forebrain bundle transection by a mechanisms not involving striatal dopamine. J Neurosci $17: 325-333$.

Ungerstedt U, Arbuthnott GW (1970) Quantitative recording of rotational behavior in rats after 6-hydroxydopamine lesions of the nigrostriatal dopamine system. Brain Res 24:486-493.

Unsicker K (1993) The trophic cocktail made by adrenal chromaffin cells. Exp Neurol 123:167-173.

Unsicker K, Krieglstein K (1995) Bovine chromaffin cells release a transforming growth factor-beta-like molecule contained within chromaffin granules. J Neurochem 65:1423-1426.

Unsicker K, Krieglstein K (1996) Growth factors in chromaffin cells Prog Neurobiol 48:307-324.

Unsicker K, Suter-Crazzolara C, Krieglstein K (1996) Growth factor function in the development and maintenance of midbrain dopaminergic neurons: concepts, facts and prospects for TGF- $\beta$. Ciba Found Symp 196:70-80.

Wachtel SR, Abercrombie ED (1994) L-3,4,-Dyhydroxyphenylalanineinduced dopamine release in the striatum of intact and 6-hydroxydopamine-treated rats: differential effects of monoamine oxidase A and B inhibitors. J Neurochem 663:108-117.

Yurek DM, Sladek JR (1990) Dopamine cell replacement: Parkinson's disease. Annu Rev Neurosci 13:415-440. 